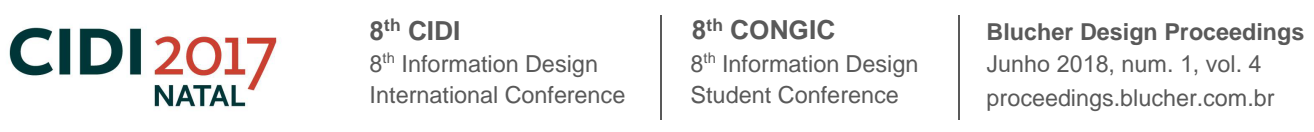

\title{
Método Lêcom: um método que envolve leiturabilidade, legibilidade e fundamentos da lectoescrita visando mensurar o rendimento da leitura de crianças brasileiras em processo de letramento \\ The Lêcom Method: a method that involves readability, legibility and the fundamentals of reading and writing, aiming to measure the reading output of Brazilian children in the literacy process
}

\section{Daniel A. Lourenço e Solange G. Coutinho}

leitura infantil, legibilidade, leiturabilidade, lectoescrita

\begin{abstract}
Este artigo objetiva apresentar um experimento piloto onde foi utilizado o Método Lêcom - que é um método voltado para mensurar o rendimento da leitura de crianças no segundo ano do ensino fundamental de escolas públicas brasileiras, a partir dos fundamentos da legibilidade e leiturabilidade, juntamente com aspectos da lectoescrita. Foram demonstradas todas as etapas do método, assim como a sua aplicação com cinco crianças do ensino fundamental da escola da rede municipal Lions Tambaú em João Pessoa, Paraíba; os resultados e a sua discussão são apresentados durante a aplicação do método.

children reading, legibility, readability, read and write

The aim of this paper is to present a pilot study in which the Lêcom Method was applied, - a method used to measure the reading output of children in the second year of primary education in Brazilian public schools. This was undertaken from the viewpoint of text legibility and readability, together with aspects of reading and writing. All stages involved in the method are demonstrated together with its application with five primary school children from the Lions Tambaú public school, in João Pessoa, in the state of Paraiba. The results and discussion are presented during the description of the method.
\end{abstract}

\section{Introdução}

O presente artigo apresenta um recorte da tese de doutorado apresentada na Universidade Federal de Pernambuco (2016), intitulada de: Desenvolvimento de um método para avaliação do rendimento de leitura com crianças brasileiras envolvendo legibilidade, leiturabilidade e fundamentos da lectoescrita, Método Lêcom.

A hipótese que norteou a pesquisa se fundamentou em investigações exploratórias nas escolas da rede pública do ensino fundamental de João Pessoa e Cabedelo e nos resultados obtidos com os questionários aplicados com os professores do primeiro e segundo ano das respectivas escolas. A hipótese ressalva a importância em unir aspectos da leitura e da escrita em um método que visa mensurar o rendimento da leitura das crianças e também resultados favoráveis nessa perspectiva.

Foi desenvolvida uma metodologia baseada na observação do ensino da leitura e da escrita realizada pelos professores, e ainda, como os conteúdos estavam sendo transmitidos para as crianças, unindo leitura e escrita. Além disso, um estudo aplicado com crianças brasileiras, mais especificamente do segundo ano do ensino fundamental de escolas públicas, visto que as mesmas se encontram em processo de letramento.

Faz-se necessário salientar que a maior parte dos testes e teorias envolvendo leitura e estudo em tipografia para crianças são advindos de fora do país e o Método Lêcom considera os aspectos sociais e culturais das escolas brasileiras, concebendo a realidade local. Outra particularidade é que em testes envolvendo rendimento de leitura na área de design, a escrita não é vista como uma variável de análise, e no método proposto a escrita foi inserida a partir da lectoescrita ${ }^{1}$. A pesquisa concentrou-se nos estudos existentes sobre lectoescrita e como

\footnotetext{
${ }^{1}$ As pesquisadoras Emília Ferreiro \& Ana Teberosky desenvolveram os estudos baseados na psicogênese da língua escrita, que tem como premissa que a aprendizagem da leitura e da escrita é um processo evolutivo. A criança formula

Anais do 8 CIDI e 8 CONGIC

Guilherme Santa Rosa; Cristina Portugal (orgs.)

Sociedade Brasileira de Design da Informação - SBDI

Natal | Brasil | 2017

ISBN 978-85-212-1305-5
} 
poderia interagir com os princípios da legibilidade e leiturabilidade, tornando-se o foco principal do estudo. Alguns autores enfatizam que existem relações entre os repertórios da leitura e escrita, em um momento inicial essas relações podem ser independentes, mas se integram à medida que algumas delas são compreendidas (Rose, 2005), sendo estas relações consideradas um dos processos da lectoescrita.

Tendo como ponto de partida evidenciar o experimento piloto da pesquisa, temos como objetivo apresentar e explanar as etapas do Método Lêcom, assim como sua aplicação e discussão dos resultados com cinco crianças da escola do ensino fundamental Lions Tambaú na cidade de João Pessoa.

Dentre as 29 escolas visitadas, a escolhida foi a Lions Tambaú por alguns fatores: (1) os professores e gestores se mostraram receptivos em relação a realizar pesquisas dentro da escola; (2) a escola se prontificou em sempre ter uma sala separada para que os testes fossem realizados e que auxiliaria o pesquisador em todos os sentidos necessários para que 0 experimento pudesse ser realizado sem transtornos; (3) A escola tinha datashow em todas as salas de aula, como o experimento piloto foi realizado com projeções de frases no quadro (explicação com maior detalhamento à frente), esperava-se que a criança já tivesse habituada a aulas com este tipo de equipamento.

Para que ocorra um entendimento dos resultados do experimento piloto é oportuno apresentar um breve panorama do referencial teórico sobre legibilidade, leiturabilidade e lectoescrita, assim como uma descrição do conjunto de etapas e ferramentas metodológicas do método proposto.

\section{Legibilidade, Leiturabilidade e Lectoescrita}

Os termos legibilidade e leiturabilidade são facilmente reconhecidos no âmbito do design, entretanto ainda apresentam ambiguidades acerca do seu significado. Desta forma descreveremos, de maneira sucinta, a acepção de cada um para melhor juízo do método construído. Ao apresentar os dois conceitos, é possível observar as diferenças principais entre os mesmos. Neste tópico será detalhado também o entendimento da lectoescrita e quais aspectos foram utilizados, visto que os três assuntos foram importantes para a elaboração do Lêcom.

Legibilidade está relacionada ao reconhecimento individual dos caracteres, de palavras e de padrões visuais, considerando os níveis de iluminação, velocidade e distância de leitura. $O$ texto deve apresentar uma orientação espacial com aspectos que favoreçam uma melhor compreensão das palavras no contexto inserido. Ainda, devem ser considerados os aspectos sociais, culturais e habilidades do leitor, assim como seu repertório léxico. Quando é voltada para os leitores iniciantes (que caracteriza a leitura como reconhecimento letra a letra, com operações de análise e síntese), os espaçamentos, o tamanho dos caracteres e a forma das palavras são determinantes para um melhor rendimento da leitura (Tinker, 1963; Lund, 1999; Sassoon \& Willians, 2000; Kato, 2007; Healy \& Cunningham, 2007; Beier, 2009; Kamikase, 2010; Gonçalves, 2010; Farias, 2013).

Em relação à leiturabilidade, deve-se considerar o quão compreensível é um texto para o leitor e os fatores pertinentes a ele, como o seu nível de compreensão, seus interesses e motivações, seu repertório léxico e o seu nível de letramento. Leiturabilidade está relacionada com atributos dos textos, enquanto que a compreensão é um atributo do leitor. Além disso, devem ser considerados alguns aspectos como a legibilidade de impressão e a apresentação visual do texto. Em poucas palavras, pode ser definido pelo quão fácil um texto pode ser lido, de modo convidativo e prazeroso para o leitor (Harrison, 1980; Aldrich \& Fennell, 1991; Sousa, 2002; Valério, 2007; Rumjanek, 2009; Kamikase et al., 2011; Fontoura \& Fukushima, 2012).

No decorrer da pesquisa exploratória com os professores do primeiro e segundo ano das escolas publicas de ensino fundamental de João Pessoa e Cabedelo, foi perceptível tanto em conversas, quanto nos questionários respondidos, o termo lectoescrita. Sendo que o maior 
destaque era para o letramento e de como o ensino da leitura e escrita se apresentavam indissociáveis. Para Rocco (1996), é possível tratar da leitura e escrita de maneira separada, entretanto, nas séries iniciais escolares, essa separação não ocorre. Ao imitar e ao recriar os modelos de textos com as quais vai interagindo, a criança incorpora novas experiências e descobertas a seus conceitos iniciais.

Ler e escrever envolve um processo contínuo de construção e reconstrução, com normas próprias do código linguístico. Até que se consiga estabelecer uma completa relação entre a fala e a escrita, o aluno precisa de uma grande e diversificada interação com a leitura e a escrita, enquanto vai construindo seu próprio conhecimento sobre o que é ler e escrever, baseando-se nos modelos que o meio social the oferece.

Portanto, entre os leitores inicias, essas atividades revelam-se como as duas faces de um fenômeno muito especial. Conforme progride a escolaridade, leitura e escrita vão sendo exploradas, desenvolvidas de forma ou mais individualizada ou então inter-relacionadas por força de constantes operações de mão dupla que vão do ler para o escrever; do escrever para o ler e assim por diante.

\section{Método Lêcom e suas etapas}

No decorrer da pesquisa, foram sendo percebidos alguns critérios importantes relacionados à leitura realizada pelas crianças, sendo eles: (1) a influência da letra do professor no quadro; (2) a vivência dos alunos com livros de diversas editoras; (3) o movimento da escrita caixa alta que é bem mais simples comparado aos outros estilos (cursivo e caixa baixa) e; (4) no segundo ano do ensino fundamental, os livros começam a apresentar a tipografia em caixa baixa (no primeiro ano é somente em caixa alta) apresentando um tipo de retrocesso no processo de leitura (de acordo com a opinião dos professores).

A influência da letra do professor foi inserida em uma das etapas do método (etapa 1) e os outros critérios estão relacionados com o que se espera do Método Lêcom, que é observar as diferenças em relação ao rendimento de leitura entre os três estilos de letras mais usuais com as quais as crianças aprendem e se familiarizam no contexto do ensino fundamental: a caixa alta, a cursiva e a caixa baixa, assim como suas preferências em relação aos três estilos. A seguir, as etapas do método (Tabela 01).

Tabela 1: Etapas e aplicabilidade do Método Lêcom. (Lourenço, 2016)

\begin{tabular}{l|l}
\hline Etapas & Aplicabilidade \\
\hline Primeira & $\begin{array}{l}\text { Construir três frases seguindo os princípios tipográficos para crianças nos três estilos: } \\
\text { caixa alta, caixa baixa e cursiva. Esta etapa deve ser realizada com o auxílio de um } \\
\text { pedagogo, que irá observar o nível de complexidade das frases. }\end{array}$ \\
\hline Segunda & $\begin{array}{l}\text { Preparar a sala de aula previamente com o Datashow, tabela de Snellen², mesa, } \\
\text { cadeira e câmera posicionados. Foram utilizados critérios ergonômicos para a } \\
\text { organização da sala de aula. }\end{array}$ \\
\hline Terceira & $\begin{array}{l}\text { Realizar a escolha do participante de forma randômica e chamar para a sala } \\
\text { previamente organizada. }\end{array}$ \\
\hline Quarta & $\begin{array}{l}\text { Convidar o participante para realizar o teste com a tabela de Snellen. Se a AV } \\
\text { (acuidade visual) estiver nos parâmetros recomendados, dar continuidade ao } \\
\text { experimento. }\end{array}$ \\
\hline Sexta & $\begin{array}{l}\text { O participante deve se sentar em outra mesa com uma cadeira. } \\
\text { Nesta mesa deve constar um lápis e uma borracha. Projetar a primeira frase (caixa } \\
\text { alta, caixa baixa ou cursiva). }\end{array}$ \\
\hline Sétima & $\begin{array}{l}\text { Pedir para o participante realizar a leitura em voz alta. Um aspecto da legibilidade. } \\
\text { Pedir para o participante copiar com sua letra a frase. A cópia auxilia o pesquisador a } \\
\text { identificar se a criança é copista (termo utilizado pelos professores quando as } \\
\text { crianças estão copiando o desenho das letras) ou se elas sabem diferenciar os } \\
\text { caracteres. }\end{array}$ \\
\hline Oitava & Pedir para o participante transcrever para o papel o que compreendeu da frase. Um \\
\hline
\end{tabular}

2 Para o teste de Snellen, houve a participação de oftalmologista, orientando o pesquisador na sua aplicação. O teste mais utilizado para acuidade visual é a escala criada pelo oftalmologista holandês Herman Snellen em 1862. Se trata de uma tabela com caracteres com tamanhos diferenciados para a leitura à distância (Zapparoli et al., 2009: 784). 


\begin{tabular}{l|l}
\hline & aspecto da leiturabilidade. \\
\hline Nona & Repetir os passos 5,6 e 7 mais duas vezes com os outros estilos de tipografia. \\
\hline Décima & Realizar o teste de preferência sobre o melhor estilo de letra para realizar a leitura. \\
\hline
\end{tabular}

Foram criadas três frases (cada frase em um estilo de letra) com conteúdos semelhantes com o auxílio do professor (as frases serão apresentadas na descrição do experimento piloto). Além disso, foi filmado o professor escrevendo as frases no quadro, já que um dos fundamentos da lectoescrita aponta que um fator positivo é a possibilidade da criança observar o ato da formação das letras e palavras antes de realizar uma leitura. Deste modo, o professor se torna um modelo de referência (Ferreiro \& Teberosky: 2007).

Devido à impossibilidade de ter o professor presente no experimento controlado, foi gerada uma animação das frases após a coleta da filmagem. Essa animação consiste em uma reprodução mais próxima possível do ato de escrita do professor. Na aplicação do método as frases são projetadas por datashow no tempo médio em que a professora utilizou para escrever cada frase ( 57 segundos no estilo caixa alta e 46 segundos nos estilos caixa baixa e cursivo) (Figura 01). As medidas de projeção foram seguidas de acordo com os fundamentos ergonômicos de lida (2005), em que a altura das letras minúsculas corresponde a $2 / 3$ da altura das maiúsculas (neste caso $-3,5$ e $5 \mathrm{~cm}$, respectivamente).

Figura 01: Tipografias e medidas utilizadas no experimento. (Lourenço, 2016)

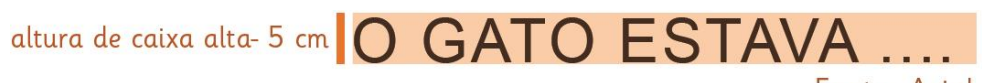

Fonte: Arial
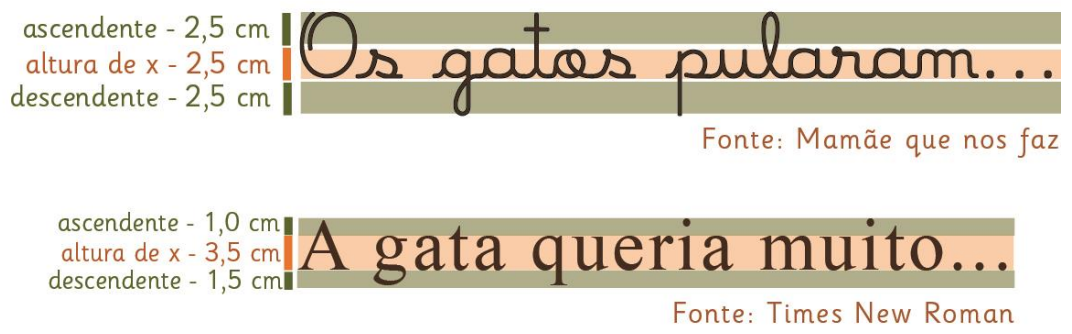

Em relação às medidas, foi considerado o, o campo de visão máxima (Figura 02) do leitor iniciante e se a projeção estaria em ângulos adequados (Figura 03).

Figura 02: Cones de visão ótima. (IIDA, 2005:29)

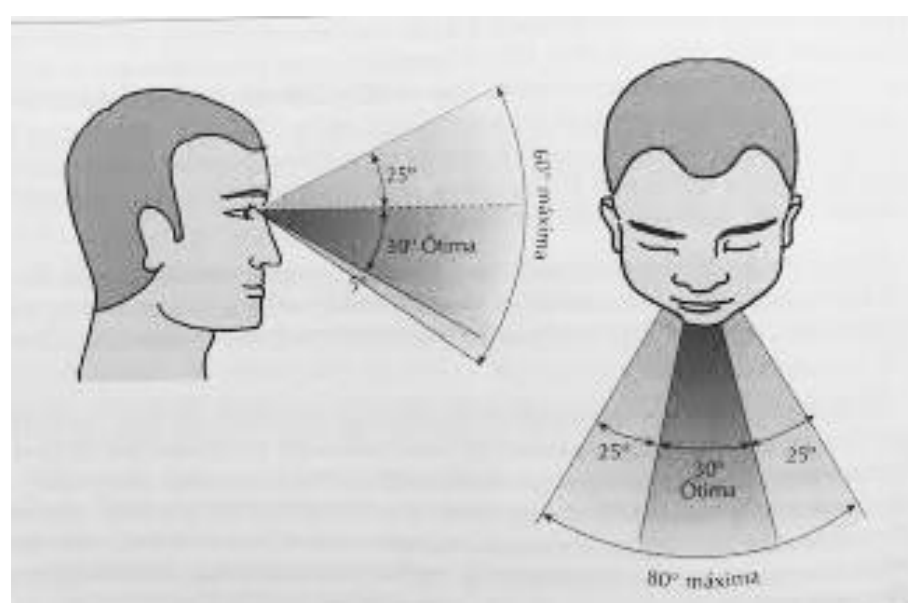

Figura 03: Ambiência do experimento piloto. (Lourenço, 2016) 


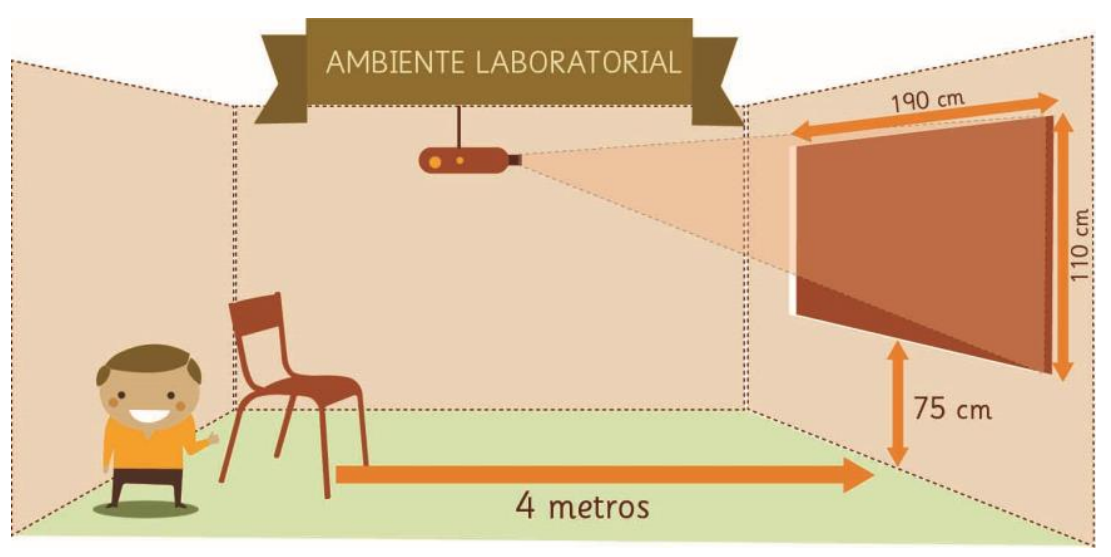

Na decima etapa, o aluno recebe uma folha com uma pergunta relacionada à sua preferência (Figura 04). O método foi aplicado em sala de aula normal, com condições de iluminação e ambiental nas quais as crianças estão habituadas.

\section{1) Qual o tipo de letra você acha mais fácil de ler:}

a) A LETRA BASTÃO

b) Cletra de mãa

c) A letra que vem nos livros

Os testes foram gravados por meio de vídeo para obter o tempo de leitura e observar quando e onde foram cometidos os erros de leitura, para posteriormente realizar uma análise qualitativa.

\section{0 experimento piloto e seus resultados}

O experimento piloto foi realizado com cinco alunos no dia 30 de julho de 2015. Neste ano a escola estava com duas turmas do segundo ano com vinte alunos cada, com as professoras Gédia Cristina e Dijanete como responsáveis.

As duas professoras apontaram que devido à greve que ocorreu nos meses de fevereiro e março de 2015 na rede municipal de ensino da cidade de João Pessoa, nem todos os alunos estavam dominando o ato da leitura, que muitos estavam na fase de reconhecimento de caracteres. De acordo com as professoras estes alunos só iriam estar prontos para conseguir ler uma palavra inteira no mês de setembro.

Sendo assim, ficou evidente que nem todas as crianças estavam letradas (termo utilizado pelas professoras para crianças que conseguem realizar uma leitura fluente); a escolha das crianças para a realização do experimento piloto foi randômica com três alunos da sala da professora Gédia Cristina e dois da sala da professora Dijanete ${ }^{3}$, com a anuência se as mesmas já se encontravam letradas ou não.

Ates de iniciar os testes, foi necessário criar um protocolo para o pesquisador. Este protocolo é importante para que haja o máximo de controle possível durante o ato do experimento com as crianças. O protocolo possui 10 etapas descritas a seguir (Tabela 02).

\footnotetext{
${ }^{3}$ Para o experimento final, foi escolhida a mesma quantidade de alunos em cada turma.
} 
Tabela 02: Protocolo para o pesquisador. (Lourenço, 2016)

\begin{tabular}{|c|c|}
\hline Primeiro passo & $\begin{array}{l}\text { O pesquisador prepara dentro da mesma sala dois ambientes para o experimento. } \\
\text { O primeiro para o teste de Acuidade Visual com a Tabela de Snellen. E o segundo } \\
\text { para o experimento de legibilidade e leiturabilidade. A câmera para a filmagem é } \\
\text { colocada ao fundo da sala. }\end{array}$ \\
\hline Segundo passo & $\begin{array}{l}\text { O pesquisador convida a criança a se sentar em uma cadeira. Logo após, explica } \\
\text { para a criança que ela irá fazer um teste para saber se esta 'tudo bem' com sua } \\
\text { visão. }\end{array}$ \\
\hline Terceiro passo & $\begin{array}{l}\text { A criança senta na cadeira e o pesquisador pede a ela que cubra o olho esquerdo } \\
\text { com uma das mãos e que observe a tabela que está colada na parede à sua frente. } \\
\text { O pesquisador explica que ela deverá dizer em voz alta qual a letra apontada. } \\
\text { Também destaca que não terá problema algum se não souber. }\end{array}$ \\
\hline Quarto passo & $\begin{array}{l}\text { No quarto passo é realizado o mesmo procedimento do terceiro. Entretanto, pede- } \\
\text { se para a criança cobrir o olho direito para que seja realizado novamente o teste } \\
\text { com as letras. }\end{array}$ \\
\hline Quinto passo & $\begin{array}{l}\text { O pesquisador pede para a criança sentar em outra cadeira, previamente } \\
\text { preparada. Ele explica que o aluno irá participar de uma pesquisa muito importante } \\
\text { para o pesquisador e que ele irá ajudar bastante. Explica como será o experimento } \\
\text { para a criança e enfatiza que se ela não conseguir ler ou escrever não terá } \\
\text { problema algum. Destaca que não se trata de uma prova e que não está 'medindo' a } \\
\text { inteligência de ninguém. }\end{array}$ \\
\hline Sexto passo & $\begin{array}{l}\text { O pesquisador pede para a criança observar a frase ser projetada e que somente } \\
\text { quando ele pedir, ela poderá ler em voz alta. Depois que ela realiza a leitura, ela } \\
\text { recebe uma folha para copiar a frase que acabou de ler. Novamente o pesquisador } \\
\text { enfatiza que não existe problema se o aluno não conseguir copiar o que estiver } \\
\text { projetado no quadro. }\end{array}$ \\
\hline Sétimo passo & $\begin{array}{l}\text { Logo após, a projeção é apagada do quadro e a folha que está na mesa com a } \\
\text { criança é trocada. É pedido para ela escrever o que ela entendeu do que acabou de } \\
\text { ler e copiar do quadro. Ela poderá avisar e passará para a próxima etapa. }\end{array}$ \\
\hline Oitavo passo & $\begin{array}{l}\text { Os mesmos passos são seguidos novamente por mais duas vezes. Projeção da } \\
\text { frase, leitura em voz alta, cópia da frase projetada e escrever o que entendeu. }\end{array}$ \\
\hline Nono passo & $\begin{array}{l}\text { Entrega-se uma nova folha para a criança e o pesquisador explica de uma maneira } \\
\text { mais simples que a pergunta que está na folha é para saber se ela (criança) tem } \\
\text { algum tipo de letra preferida ou que acha mais fácil de ler. O pesquisador mostra os } \\
\text { três tipos de letras que foram utilizadas nas frases projetadas do experimento }\end{array}$ \\
\hline Décimo passo & $\begin{array}{l}\text { O pesquisador comunica a criança que o teste acabou. Agradece pela sua } \\
\text { participação, avisa novamente que sua participação foi de grande importância para } \\
\text { a pesquisa e pede para sair da sala e chamar o outro colega de sala. }\end{array}$ \\
\hline
\end{tabular}

Ao entrar na sala de aula o pesquisador realizou a escolha de forma aleatória e a professora sinalizava com a cabeça se a criança era letrada ou não. Foi a maneira mais simples de realizar a escolha sem a interferência das professoras por crianças que poderiam apresentar um nível mais elevado de leitura que as outras. Realizada a escolha, as crianças eram chamadas uma a uma para a sala previamente preparada. Em seguida a análise dos cinco alunos que participaram do piloto ${ }^{4}$.

Participante A: O participante $A$ é do sexo masculino tem sete anos e pertence à sala da professora Gédia Cristina. No teste de AV o aluno não apresentou nenhum problema para ler as letras. Em relação à sua preferência destacou que prefere ler com a letra de mão (cursiva). O teste todo teve duração de vinte e dois minutos e os dados estão compilados na tabela 03.

Tabela 03: Dados do experimento com o participante A. (Lourenço, 2016)

${ }^{4}$ É importante ressaltar que o experimento piloto foi aprovado e seguiu todos os trâmites exigidos pelo Comitê de Ética da UFPE. 


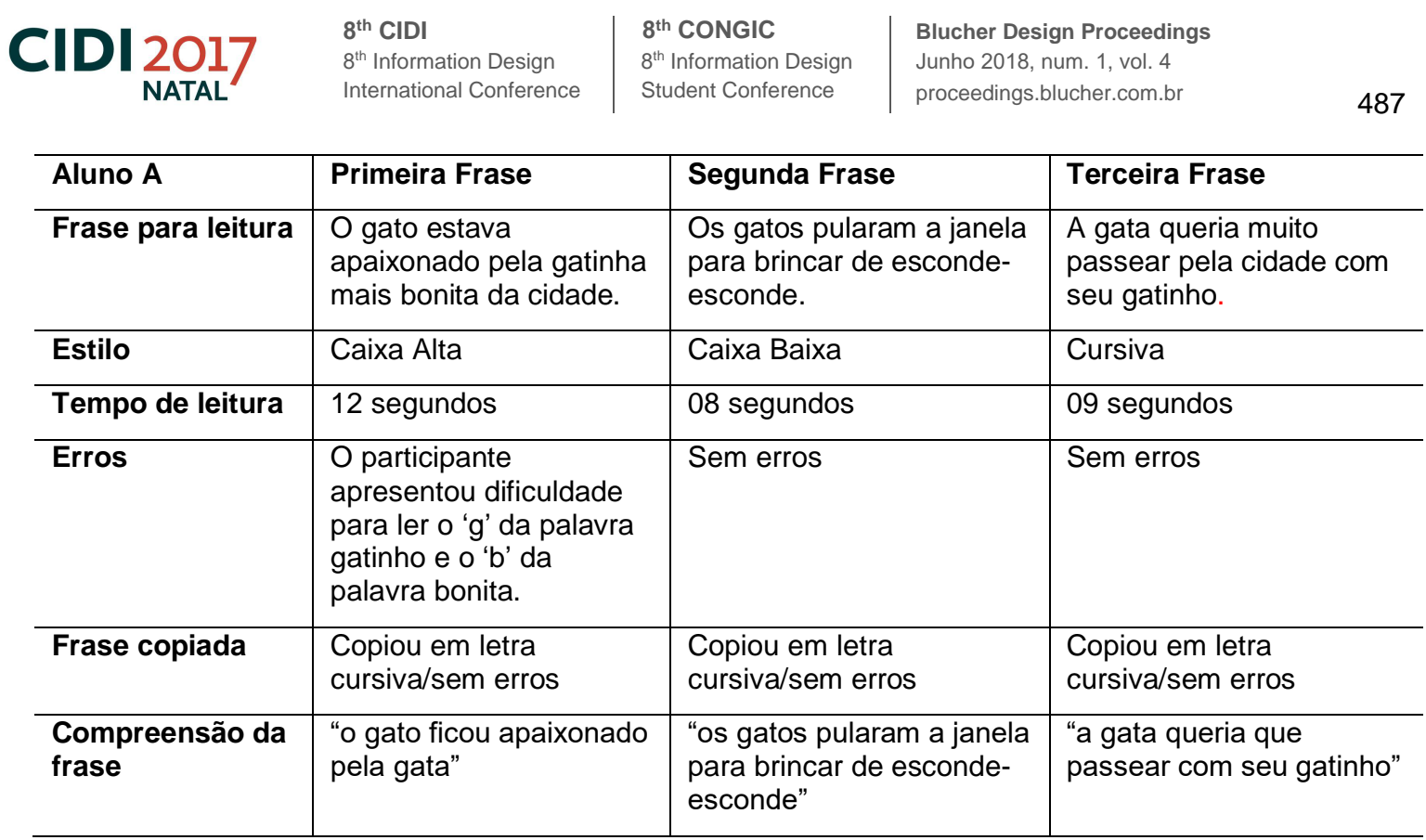

Participante B: O participante B é do sexo masculino, tem sete anos e faz parte da turma da professora Gédia Cristina. No teste de AV o aluno não apresentou nenhum problema para leitura. Sua visão foi considerada adequada para continuar com o experimento.

Um fator curioso é que este participante se diferenciou dos demais em relação a sua preferência pelo tipo de letra, preferia a letra "que vem nos livros" (caixa baixa). Pode-se inferir que este é um aluno que apresenta a aquisição do ato da leitura e que conhece todos os tipos de letras apresentadas, pois não apresentou dificuldades de leitura e nem de compreensão (Tabela 04). O teste teve duração de 20 minutos.

Tabela 04: Dados do experimento com o participante B. (Lourenço, 2016)

\begin{tabular}{l|l|l|l}
\hline Aluno A & Primeira Frase & Segunda Frase & Terceira Frase \\
\hline $\begin{array}{l}\text { Frase para } \\
\text { leitura }\end{array}$ & $\begin{array}{l}\text { Os gatos pularam a } \\
\text { janela para brincar de } \\
\text { esconde-esconde. }\end{array}$ & $\begin{array}{l}\text { A gata queria muito } \\
\text { passear pela cidade com } \\
\text { seu gatinho. }\end{array}$ & $\begin{array}{l}\text { O gato estava apaixonado } \\
\text { pela gatinha mais bonita } \\
\text { da cidade. }\end{array}$ \\
\hline Estilo & Caixa Alta & Caixa Baixa & Cursiva \\
\hline $\begin{array}{l}\text { Tempo de } \\
\text { leitura }\end{array}$ & 07 segundos & 07 segundos & 07 segundos \\
\hline Erros & Sem erros & Sem erros & Sem erros \\
\hline Frase copiada & $\begin{array}{l}\text { Copiou em letra } \\
\text { cursiva/sem erros }\end{array}$ & $\begin{array}{l}\text { Copiou em letra } \\
\text { cursiva/sem erros }\end{array}$ & $\begin{array}{l}\text { Copiou em letra } \\
\text { cursiva/sem erros }\end{array}$ \\
\hline $\begin{array}{l}\text { Compreensão } \\
\text { da frase }\end{array}$ & $\begin{array}{l}\text { "Os gatos pularam a } \\
\text { janela para brinca" }\end{array}$ & $\begin{array}{l}\text { "A gata queria passea } \\
\text { muito pela cidade" }\end{array}$ & $\begin{array}{l}\text { "ele estava paixonado } \\
\text { pela gatinha mais bonita } \\
\text { da cidade" }\end{array}$ \\
\hline
\end{tabular}

Participante C: O participante C é do sexo feminino, tem sete anos e faz parte da turma da professora Dijanete. No teste de AV a aluna não apresentou nenhum problema para ler as letras. Sua visão foi considerada adequada para continuar com o experimento.

Na primeira frase que a aluna deveria escrever o que havia compreendido, não soube o que escrever. Ficou pensativa e em dúvida. Todavia, nas outras duas frases, escreveu com facilidade o que havia compreendido.

Uma das conclusões é que a aluna entendeu muito bem o que lia e copiava, mas, como não foi explicado (previamente) que ela iria escrever o que tinha entendido, ficou mais preocupado 
em ler de uma forma correta e rápida. Em relação à preferência do tipo de letra, prefere a letra de mão (cursiva). O teste teve duração de vinte e três minutos (Tabela 05).

Tabela 05: Dados do experimento com o participante C. (Lourenço, 2016)

\begin{tabular}{l|l|l|l}
\hline Aluno A & Primeira Frase & Segunda Frase & Terceira Frase \\
\hline $\begin{array}{l}\text { Frase para } \\
\text { leitura }\end{array}$ & $\begin{array}{l}\text { A gata queria muito } \\
\text { passear pela cidade } \\
\text { com seu gatinho. }\end{array}$ & $\begin{array}{l}\text { Os gatos pularam a janela } \\
\text { para brincar de esconde- } \\
\text { esconde. }\end{array}$ & $\begin{array}{l}\text { O gato estava apaixonado } \\
\text { pela gatinha mais bonita } \\
\text { da cidade. }\end{array}$ \\
\hline Estilo & Caixa Alta & Caixa Baixa & Cursiva \\
\hline $\begin{array}{l}\text { Tempo de } \\
\text { leitura }\end{array}$ & 06 segundos & 12 segundos & 10 segundos \\
\hline Erros & Sem erros & Sem erros & Sem erros \\
\hline Frase copiada & $\begin{array}{l}\text { Copiou em letra } \\
\text { cursiva/sem erros }\end{array}$ & $\begin{array}{l}\text { Copiou em letra } \\
\text { cursiva/sem erros }\end{array}$ & $\begin{array}{l}\text { Copiou em letra } \\
\text { cursiva/sem erros }\end{array}$ \\
\hline $\begin{array}{l}\text { Compreensão } \\
\text { da frase }\end{array}$ & Não soube responder & $\begin{array}{l}\text { "Os gatos pularam na } \\
\text { janela para brincade de } \\
\text { esconde esconde" }\end{array}$ & $\begin{array}{l}\text { "O gato estava } \\
\text { apaixonado pela gatinha } \\
\text { mais bonita da cidade" }\end{array}$ \\
\hline
\end{tabular}

Participante D: O participante $D$ é do sexo feminino, tem sete anos e faz parte da turma da professora Dijanete. No teste de AV a aluna não apresentou nenhum problema para ler as letras. Sua visão foi considerada adequada para continuar com o experimento. O participante preferiu a letra bastão para leitura (Tabela 06).

Tabela 06: Dados do experimento com o participante D. (Lourenço, 2016)

\begin{tabular}{|c|c|c|c|}
\hline Aluno A & Primeira Frase & Segunda Frase & Terceira Frase \\
\hline $\begin{array}{l}\text { Frase para } \\
\text { leitura }\end{array}$ & $\begin{array}{l}\text { A gata queria muito } \\
\text { passear pela cidade } \\
\text { com seu gatinho. }\end{array}$ & $\begin{array}{l}\text { O gato estava apaixonado } \\
\text { pela gatinha mais bonita } \\
\text { da cidade. }\end{array}$ & $\begin{array}{l}\text { Os gatos pularam a janela } \\
\text { para brincar de esconde- } \\
\text { esconde. }\end{array}$ \\
\hline Estilo & Caixa Alta & Caixa Baixa & Cursiva \\
\hline $\begin{array}{l}\text { Tempo de } \\
\text { leitura }\end{array}$ & 06 segundos & 06 segundos & 05 segundos \\
\hline Erros & Sem erros & Sem erros & Sem erros \\
\hline Frase copiada & $\begin{array}{l}\text { Copiou em letra } \\
\text { cursiva/sem erros }\end{array}$ & $\begin{array}{l}\text { Copiou em letra } \\
\text { cursiva/sem erros }\end{array}$ & $\begin{array}{l}\text { Copiou em letra } \\
\text { cursiva/sem erros }\end{array}$ \\
\hline $\begin{array}{l}\text { Compreensão } \\
\text { da frase }\end{array}$ & $\begin{array}{l}\text { "ela queria Pasia com } \\
\text { seu filho" }\end{array}$ & "o Gato Gostava da Gata" & $\begin{array}{l}\text { "O Gato queria ficar } \\
\text { brincano na janela da } \\
\text { dona" }\end{array}$ \\
\hline
\end{tabular}

Participante E: A participante E é do sexo feminino, tem sete anos e faz parte da turma da professora Gédia Cristina. No teste de AV a aluna não apresentou nenhum problema para ler as letras. Sua visão foi considerada adequada para continuar com o experimento. A participante apresentou dificuldades para ler algumas palavras (Tabela 07). O teste teve duração de vinte minutos e em relação à preferência do tipo de letra, prefere a letra de mão (cursiva). 
Tabela 07: Dados do experimento com o participante D. (Lourenço, 2016)

\begin{tabular}{l|l|l|l}
\hline Aluno A & Primeira Frase & Segunda Frase & Terceira Frase \\
\hline $\begin{array}{l}\text { Frase para } \\
\text { leitura }\end{array}$ & $\begin{array}{l}\text { Os gatos pularam a } \\
\text { janela para brincar de } \\
\text { esconde-esconde. }\end{array}$ & $\begin{array}{l}\text { O gato estava apaixonado } \\
\text { pela gatinha mais bonita } \\
\text { da cidade. }\end{array}$ & $\begin{array}{l}\text { A gata queria muito } \\
\text { passear pela cidade com } \\
\text { seu gatinho. }\end{array}$ \\
\hline Estilo & Caixa Alta & Caixa Baixa & Cursiva \\
\hline $\begin{array}{l}\text { Tempo de } \\
\text { leitura }\end{array}$ & 21 segundos & 28 segundos & 25 segundos \\
\hline Erros & $\begin{array}{l}\text { Apresenta dificuldades } \\
\text { de leitura na união das } \\
\text { sílabas. Exemplos: } \\
\text { Pula-ra; brinnnn-car; } \\
\text { esconnn-de; jannneee- } \\
\text { la. }\end{array}$ & $\begin{array}{l}\text { Apresentou erros } \\
\text { semelhantes: } \\
\text { a-pai-xo-nnnna-do; ga-ti- } \\
\text { na; bo-nnnnnit-ta. }\end{array}$ & $\begin{array}{l}\text { Apresentou erros } \\
\text { semelhantes: } \\
\text { Mmmui-to; passsi-á; } \\
\text { peeee-la; ga-te-nha }\end{array}$ \\
\hline Frase copiada & $\begin{array}{l}\text { Copiou em letra } \\
\text { cursiva/sem erros }\end{array}$ & $\begin{array}{l}\text { Copiou em letra } \\
\text { cursiva/sem erros }\end{array}$ & $\begin{array}{l}\text { Copiou em letra } \\
\text { cursiva/sem erros }\end{array}$ \\
\hline $\begin{array}{l}\text { Compreensão } \\
\text { da frase }\end{array}$ & $\begin{array}{l}\text { "Os GATOs polema } \\
\text { JAnela" }\end{array}$ & "a Gata tavana cidade" & "o gato e panarua cidade" \\
\hline
\end{tabular}

Os dados de todos os participantes foram compilados em uma tabela (Tabela 08).

Tabela 08: Dados obtidos com o experimento piloto. (Lourenço, 2016)

\begin{tabular}{|c|c|c|c|c|c|}
\hline Participantes & $\begin{array}{l}\text { Caixa alta/ Erros } \\
\text { Tempo/ Número }\end{array}$ & $\begin{array}{l}\text { Caixa Baixa/ Erros } \\
\text { Tempo/ Número }\end{array}$ & $\begin{array}{l}\text { Cursiva/ Erros } \\
\text { Tempo/ Número }\end{array}$ & Preferência & Compreensão \\
\hline A & $12^{\prime} / 2$ & 8'/ ---- & 9'/ ---- & Cursiva & 3 \\
\hline B & 7'/ ---- & 7'/ ---- & 7'l ---- & $\begin{array}{l}\text { Caixa } \\
\text { baixa }\end{array}$ & 3 \\
\hline C & 6'/ ---- & 12'/ ---- & 10 '/ ---- & Cursiva & 2 \\
\hline D & 6'/ ---- & 6'/ ---- & 5'/ ---- & Caixa alta & 3 \\
\hline$E$ & $21 \% / 4$ & $28 ' / 3$ & $25 \% / 3$ & Cursiva & 3 \\
\hline Total & 52 '/ 4 & $61^{\prime \prime} / 3$ & 53 '/ 3 & & \\
\hline Média & $10,4^{\prime} / 0,8$ & $12,2^{\prime} / 0,6$ & 11,2 ' 0,6 & & \\
\hline
\end{tabular}

Percebem-se nos dados da tabela que a média de tempo de leitura (em segundos) nos três estilos de letras é muito similar, sendo que a média da leitura em caixa alta foi a menor $\left(10,4^{\circ}\right)$, seguidos da letra cursiva $\left(11,2^{\prime}\right)$ e da caixa baixa $\left(12,2^{\prime}\right)$. Entretanto, a média de erros da letra caixa alta se apresentou maior que as demais, 0,8 para 0,6 (caixa baixa e cursiva).

Mais da metade das crianças apontou que prefere a letra cursiva para realizar a leitura. Uma destacou que prefere a letra caixa baixa e outra a caixa alta. Grande parte dessa preferência pode ser intrínseca à letra do professor em sala de aula e ao período de aprendizagem de escrita que os alunos se encontram na escola, sabendo que no segundo ano estão realizando a aquisição da escrita e leitura em estilo cursivo.

Em relação ao piloto, como todas as crianças estavam em um mesmo nível de letramento, e com uma leitura fluente, as médias, tanto do tempo de leitura, quanto dos erros cometidos foram muito similares nos três estilos, demonstrando que para as crianças que já possuem em seu repertório os três estilos tipográficos, não importa o estilo da letra para a leitura.

Todos os alunos conseguiram escrever o que compreenderam das frases lidas, apenas um não escreveu o que compreendeu de uma frase. É importante destacar que foi considerado 


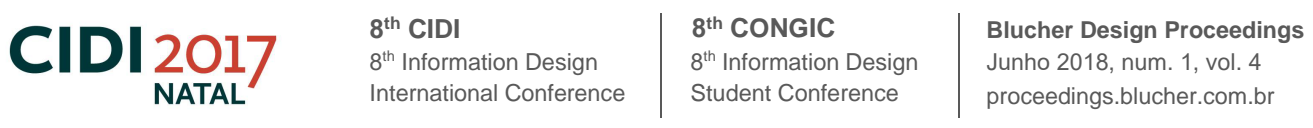

como "frase compreendida" quando o aluno conseguiu transcorrer com suas palavras o que ele absorveu da frase lida, ou seja, se o aluno conseguiu escrever um conteúdo lógico que remetesse a frase lida era considerado como "frase compreendida".

Pôde-se perceber que a criança que realiza a cópia das frases em letra cursiva geralmente consegue explicar o conteúdo do que compreendeu com maior destreza. Nestes casos, constata-se que a criança já não é mais um copista e sim que se encontra em fase de letramento decifrando todos os signos do alfabeto em diferentes estilos.

\section{Considerações Finais}

Este artigo tratou de demonstrar como foi gerado e aplicado o experimento piloto de uma pesquisa mais abrangente. $O$ teste foi de extrema importância para poder observar como o pesquisador deveria reagir enquanto aplicava e também para perceber se seriam necessárias mudanças para a aplicabilidade do experimento final.

Apesar de não apresentar os dados do delineamento experimental final pode-se inferir que um método, que faz a associação dos fundamentos da legibilidade, leiturabilidade e fundamentos da lectoescrita, se apresenta de forma eficaz para mensurar dados relativos à leitura e sua compreensão, pois considera a criança e seu grau de instrução dentro da sala de aula e também fora dela; assim sendo, considera as diferenças de letramento dentro de um ambiente escolar, muitas vezes relacionando com o meio e as relações em que a criança vive.

\section{Referências Bibliográficas}

ALDRICH-RUENZEL, N.; FENNELL, J. (Eds). 1991. Designer's Guide to Typography. Nova lorque: Watson Guptill Publications.

BIZZOTTO, I. M.; AROEIRA L. M.; PORTO A. 2010. Alfabetização Linguística: da teoria à prática. 1를 Edção. Belo Horizonte: Editora Dimensão.

BEIER, S. 2009. Typeface Legibility: towards defining familiarity. 268 f. Tese (P.H.D) - Royal College of Art. Londres. Disponível em:

<http://researchonlinerca.ac.uk/957/1/Sofie_Beier_Typeface_Legibility_2009.pdf> Acesso em: 15 de agosto de 2012.

FARIAS, P. L. 2013. Tipografia digital. O impacto das novas tecnologias. 4⿳亠丷厂 Edição, Teresópolis: $2 \mathrm{AB}$.

FERREIRO, E.; TEBEROSKY, 2007 A. Psicogênese da Língua Escrita. 4ª ed. Porto Alegre: Artes Médicas.

FONTOURA, A. M.; FUKUSHIMA, N. 2012. Vade-mécum de Tipografia. Curitiba: Editora Insight.

GONÇALVES, C. H. C. 2010. Estudo da metodologia de projeto gráfico aplicado ao contexto de uma empresa jornalística, (Dissertação de Mestrado em Design, não publicada). Faculdade de Arquitetura, Artes e Comunicação, Universidade Estadual Paulista, Bauru.

HARRISON, C. 1980. Readability in the classroom. Nova lorque: Cambridge University Press.

HEALY, A. F.; CUNNINGHAM, T. F. 1992. A developmental evaluation of the role of word shape in word recognition. Memory and Cognition v.20, n.2, p. 141-150.

IIDA, I. 2005. Ergonomia: projeto e produção. São Paulo: Edgard Blücher.

KAMIKASE, M. S.; NASCIMENTO R. A.; SANTOS J. E. 2011. Bulas e Cartelas de Medicamentos: Possíveis soluções de leiturabilidade através do Design Gráfico. Revista ARCOS DESIGN, v. 6, n. 1 p.42-59, Rio de Janeiro.

KATO, M. 1985. O aprendizado da leitura. São Paulo: Martins Fontes.

LUND, O. 1999. Knowledge construction in Typography: the case of legibility research in the legibility of sans serif typefaces, (Tese de Doutorado não publicada), Department of Typography \& Graphic Communication, The University of Reading, Reino Unido. 
LOURENÇO, D. A. 2016. Desenvolvimento de um método para avaliação do rendimento de leitura com crianças brasileiras envolvendo legibilidade, leiturabilidade e fundamentos da lectoescrita - Método Lêcom. (Tese de Doutorado não publicada), Departamento de Design, Universidade Federal de Pernambuco, UFPE, Recife.

ROCCO, M. T. F. 1996. Leitura e escrita na escola: algumas propostas. Brasília: Em Aberto. Ano 16, n.69, jan./mar.

ROSE, J. 2005. Análise Comportamental da aprendizagem da leitura e escrita. Revista Brasileira de Análise do Comportamento. Brazilian Journal of Behavior Analysis, v.1, n.1, p. 2950.

RUMJANEK, L. 2009. Construção de textos para estudo de legibilidade com crianças em processo de alfabetização. $9^{\circ}$ USIHC: Curitiba.

SASSOON, R.; WILLIAMS, A. 2000. Why sasson? Material complementar que acompanha a tipografia Sassoon. Londres.

SOUSA, M.2002. Guia de Tipos: Métodos para o uso de fontes em PC. Disponível em:< www.guiadetipos.pt.vu> Acesso em: 22 de agosto de 2012.

TINKER, M. 1963. A. Legibility of print. Ames: lowa State University Press.

VALÉRIO, M. Â. F. M. 2007. Uma Prevenção para Todos? Análise do Grau de Leiturabilidade, Peso da Régua.

ZAPPAROLI, M; KLEIN, F; MOREIRA, H. 2009. Avaliação da Acuidade Visual Snellen. Arquivo Brasileiro de Oftalmologia, v.72, n.6, p. 12-15. Curitiba.

\section{Sobre o(a/s) autor(a/es)}

Daniel Alvares Lourenço; Dr, IFPB, Brazil <lourencodesign@gmail.com>

Solange Galvão Coutinho, PhD, UFPE, Brazil <solange.coutinho@globo.com> 